\title{
Lateral Leadership - A Critical Literature Review of a Fundamental Leadership Approach
}

\author{
Sascha Klein ${ }^{\# 1}$ \\ ${ }^{\#}$ Faculty of Business and Economics, Mendel University \\ ${ }^{1} \mathrm{xklein} 3 \mathrm{emendelu.cz}$
}

\begin{abstract}
In this article we examine the concept of Lateral Leadership, we examine the research question 'Is the concept of Lateral Leadership a fundamental Leadership approach or only a limited leadership method?" by an extensive literature review of the topic of leadership and its multiple theories. We define a research state for the topic Leadership and for the topic Lateral Leadership.

The method of Qualitative Content Analysis as outlined by Mayring has been used to analyse the literature and interpret the findings. We further analyse the Leadership Influencing Forces that make up the concept of Lateral Leadership and show how the Leadership Influencing Factors develop and how they interact with each other.

We show that the concept of lateral leadership has a claim to be perceived as a comprehensive model of Leadership rather than as a limited method and discuss the possibilities of empirical underpinning our results through future research.
\end{abstract}

Keywords_Leadership, Leadership Influencing Factors, Trust, Power, Understanding

\section{INTRODUCTION}

According to today's findings, it is no longer possible to prove since when leadership has played a decisive role in human society and in the organization of groups in the history of mankind. It remains to be assumed that in the context of the increasing socialization of human beings and the associated division of labour, there has been a need for an effective and efficient allocation of resources. There was a need for someone to allocate the existing resources of the group and direct the forces in such a way that a given goal could be achieved. Whether this is to be successful in hunting within a group of early humans or to have a team of experts produce results as part of a project work, the need for leadership is ubiquitous and still present.

The phenomena of leadership have not only been researched before this article, but there are already numerous publications, theories and models on the topic of leadership.

Nieder describes that it has long been tried to find out which personality traits distinguish a leader. This property-based leadership theory has failed to find a general factor of 'leadership talent' [39].

The search for the Great Man theory dates to Carlyle's research in 1888. The theory revolves around the phenomenon of charismatic leadership, the qualities of which predestined a leader to lead. According to Neuberger, the property-theoretical approach of leadership research was overestimated in its early days, heavily criticized and considered outdated, only to find recognition in parts afterwards[19].

Lewin conducted the first studies on the effects of different leadership styles in 1939. This led to the emergence of the concepts of authoritarian, laissez-faire and democratic leadership. Wunderer and Grunwald then added the cooperative leadership style to these classifications in 1980. Authoritarian leadership means that all decisions are made by the leader alone. These are translated into clear instructions, and their compliance is checked [43].

Democratic leadership means that decisions consider employee assessments, right up to the group's decision. Goals are found by the group and implemented together. Laissez-faire style means that the manager does not have to direct the employees in concrete terms. Instructions are only vague and non-binding. Lewin sums up that a democratic leadership style seems most successful, as it includes the commitment of the followers[19].

Atthe 1950s, elaborate empirical studies were repeatedly carried out in order to further advance leadership research. Here are Blake and Mouton (1964) and Tannenbaum and Schmidt (1973)to be mentioned[4], [40]. As part of the 'Ohio Studies', Fleishman, Haplin, Winer, Hemphill and Coons (1956) extracted two overarching leadership dimensions by factor analysis. These were referred to as Consideration and Initiating Structure. Employee-oriented leadership treats employees equally and takes up their suggestions. Appreciation for good work reinforces the self-esteem of employees. Task-oriented leadership 
organizes and initiates the actions of employees and insists on compliance with standards and deadlines. The role of the employees is clearly defined, and the manager decides what to do by whom [11].

The four-field model was developed in 1977 by Hersey and Blanchard on the basis of the two management dimensions of employee and task orientation. Depending on the degree of maturity of the guided, the model recommends a particular appropriate leadership behaviour. The four basic styles are distinguished based on motivation and competence. These are Telling (dictating and directing, efficient at low maturity), Selling (arguing and convincing, efficient with average maturity), Participating (encouraging and involving, efficient at moderate to high maturity) and delegating (delegating and empowering, efficient with high maturity). The model is particularly popular with practitioners and is often used for executive development. in the context of scientific researchwith regard to theoretical research, logical stringency and consistency, it is regarded more like a naive theory of everyday life [17].

Burns researched the behaviour of a political leader in 1978 and developed the distinction between transactional and transformational leadership. By continuously strengthening the desired behaviour through recognition or financial reward, an increase in performance of the employees and more job satisfaction is predicted [19].

Bass and Avolio (1994) developed the concept of transformational leadership. This goes beyond the concept of transactional leadership and strives for an inner transformation of the fundamental goals of the guided and a higher degree of maturity of the satisfaction of the needs of the guided. To create this, executives need to be convincing and build a trusting relationship with their employees. The following essential strategies of transformational leadership are described by Bass and Avolio [2]. Idealized influence (charisma), inspirational motivation, intellectual stimulation and individualized attention. Idealized influence means that the leader shows conviction, emphasizes trust, clearly positions himself and assumes ethical responsibility even on critical issues. Inspiring motivation means that the leader formulates an attractive vision for the future and emphasizes the importance of upcoming tasks. Overall, he is optimistic, committed and enthusiastic. Intellectual stimulation means that the follower who is supported by the leader take a critical attitude towards the status quo and reward the leader by coming up with creative solutions and inspirations.

Individualized attention means that the leader considers the skills and individual needs of the follower. There is broad agreement that the transformational leadership style has a positive effect on the performance of the followers. Numerous recent studies and meta-analyses confirm the positive impact on employee satisfaction, trust and commitment. Judge et al. (2004) and Piccolo et al. (2012) are examples of relevant studies [34], [19].

Jung et al. (2008) were also able to demonstrate a definite link between a company's ability to innovate and a transformational management style[18].

Hinkin and Tracey (1999) demonstrated that, especially in times of radical change, or when leaders cannot directly assess the work of their followers, a transformational leadership style is a potential success factor[19]. Wegge and Rosenstiel (2002) summarize that there are hardly any limits, especially in times of the progressive digitalization of the mediation of a shared vision through modern communication technologies[36].

Nerdinger explains that transactional leadership is based on the principle of reinforcement. In doing so, the leader controls the path taken by his followers in pursuing their goals. In comparison, transformational leadership starts with the regular effort of the employees and transforms them to a higher level of effort [32].

Yukl points out that the classic approaches of leadership research have repeatedly tried in recent decades to find out which factors make a successful leadership. The research focused primarily on the topic of 'personality of the leader' and his 'leadership behaviour'. However, it is repeatedly noted that the personality of the leader and his behaviour can only represent one side of the view since leadership is also created in the mind of the followers [16].

It can be noted that the existing research on leadership is extensive and it remains to be examined what role the concept of lateral leadership plays in this context.

\section{METHODS}

This research intends to answer the following research question:

'Is the concept of Lateral Leadership a fundamental Leadership approach or only a limited leadership method.'

To answer the proposed research question an extensive literature review and a qualitative literature analysis was performed.

For this purpose, the following databases/library catalogues were used for literature searches:

- $\quad$ SpringerLink

- $\quad$ SCOPUS 
- JSTOR

- $\quad$ ABS Academic Journal Quality Guide

- $\quad$ PROQuest

- $\quad$ EBSCO Host

- $\quad$ Online Katalog der HSU Hamburg

- $\quad$ beluga -Online Katalog der Hamburger Bibliotheken

- Google Scholar

- Google Search

The following search terms were used as part of a targeted literature search:

- $\quad$ Lateral leadership

- $\quad$ Lateral Leadership

- Lateral Leadership Sales

- Leadership

- Leadership+without authority

- Influencing Factors+Leadership

- Motivation+Leadership

- $\quad$ Personality Factors+Leadership

- $\quad$ BFI+Leadership

The literature research identified 765 potential sources, 353 of which were identified as relevant sources. All sources that corresponded to the generally valid scientific requirement for the level of detail and quality of the elaboration were classified as relevant.

250 primary sources were used in this work. These are all scientific publications and articles in scientific journals. These are mainly more recent works with a publication date above 1990. A few works explaining generally accepted scientific foundations are even older than the previous mentioned. The oldest work used is the 1888 publication 'on heroes, hero worship and the heroic in history' by Carlyle [7]. The most recent work used is 'Trust and Power' by N. Luhmann from 2018[29].

This literature has been coded with the MaxQDA software. For this purpose, 9 main codes and 23 sub codes were defined inductively and deductively, and the present literature was encoded according to the method of structured content analysis. For this purpose, passages were encoded in 1953 codings and subsequently analysed in relation to the research questions.

For an overview of the Structured Content Analysis approach, see Figure 1. 


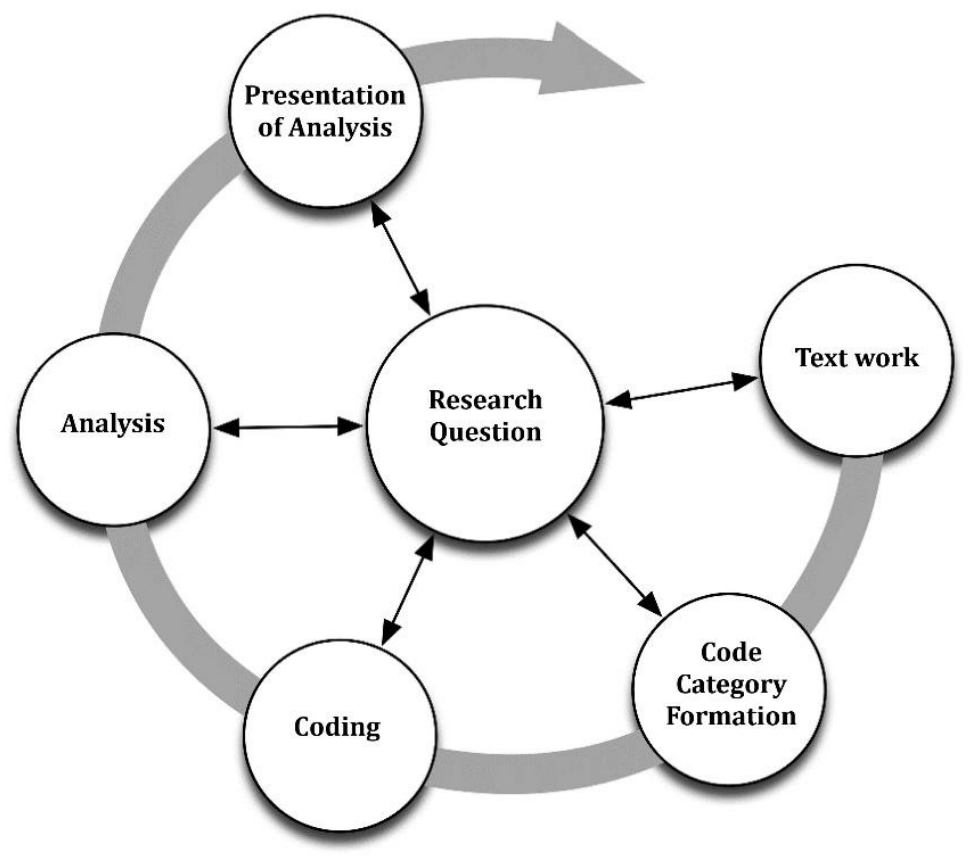

Figure 1: Procedure Structured Content Analysis [23]

For an overview of the created codes and subcodes, as well as their hierarchy, see Figure 2.

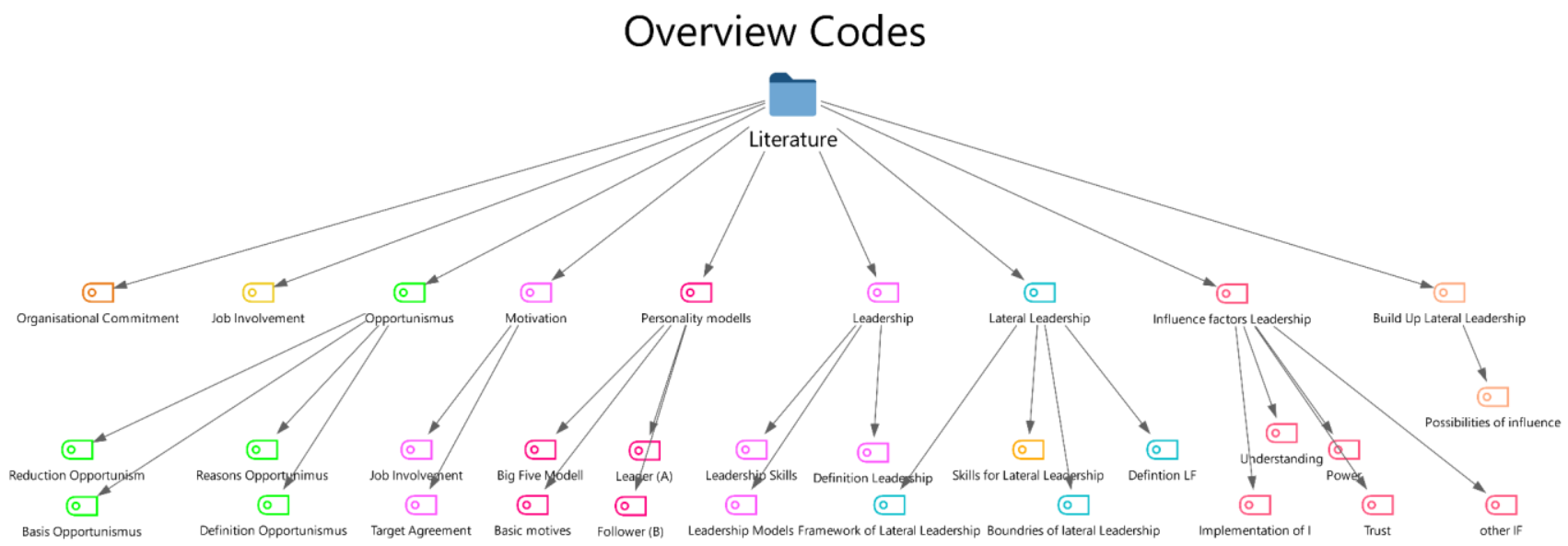

Figure 2: Overview of Literature Codes

\section{RESULTS AND DISCUSSION}

As already mentioned, leadership is understood in the traditional sense as external control of employees. In the modern sense, however, leadership is to be seen as a contribution to the self-organization of employees and their willingness to organize themselves[37].

This modern understanding of leadership also show in the concept of lateral leadership. Less as a concept for controlling employees, but rather in the sense of supporting employees through targeted and meaningful influence by the leader in order to encourage the employees to perform at their best.

The concept of lateral leadership is primarily based on the work of the organizational sociologist Prof. Dr. Stefan Kühl from Bielefeld University[26]. 
Kühl subsumed, any employee is always guided laterally, even if a hierarchy exists. Kühl shows that in the actions of many decision-makers, situations arise again and again in which a decision has to be made without being able to resort to the formal hierarchy.

Lateral leadership is a guiding technique and is part of the trend towards post-heroic management, as it aims to demonstrate a systematic approach to the organisation, which only partly draws on personal leadership skills [26].

Kühl cites the three central mechanisms of influence as understanding, power and trust [26].

Kühlsubsumes that any form of guidance can be attributed to these three central mechanisms of influence. This is also found in other research.

Geramanis subsumes that lateral leadership is about considering tactics, practices and manoeuvres of influence against the background of the processes in the organization [14].

In 2012, Solga and Blickle identified four dimensions of micropolitical competence. These are social acumen, networking, perceived sincerity and interpersonal influence. Social acumen means having the ability to observe others attentively and sensitively, to interpret their behaviour correctly and adjust one's own behaviour appropriately. Network ability means to enter into trusting relationships, to position oneself well and to support others according to the principle of reciprocity. Perceived sincerity means influencing others in such a way that they do not perceive it as manipulative or self-serving. Interpersonal influence means choosing and applying influence tactics flexibly and, in a situation,appropriate manner in order to control one's own environment without acting manipulatively or unfairly [16].

This 'influence' through understanding, trust and power naturally work not only from leader to follower but also in other possible constellations.

Leadership, in the concept of lateral leadership, is less tied to a formal position than to a behaviour. Thus, people outside the formal hierarchy can lead by interacting to influence the behaviour and experience of other people[39].

It should also be noted that these named mechanisms of influence often operate in secret. Luhmann noted in 1984 that the processes of power, trust and understanding are mostly delayed. This means that they run in secret, as their visibility would limit or even completely destroy their effectiveness [26].

It should be noted that all that is not visible and thus takes place outside the functional hierarchy of the organization, in most cases, unobserved and thus not perceived at all by most of the participants.

Through this approach, the concept of lateral leadership offers a leadership approach based on meaningful influence and is clearly different from other leadership concepts, since, in the concept of lateral leadership, the use of hierarchical leadership is mostly based on the use of hierarchical authority is deliberately waived, or is assumed that it does not exist.

Possible areas of application of lateral leadership is thus any conceivable management situation in which there is no direct authority to direct, as in cross-departmental project teams, in the management of matrix organizations, in cooperation with outsourced business units or in any management situation in which the exercise of direct authority should be better dispensed with. In the existing literature, this is processed in many facets.

Value chains increasingly consist of cooperation's, permanent or temporary ones, in which there is no authority to direct in the event of a case [26].

Useem and Harder summarize that beyond the formal authority of a manager, where negotiations or convictions must be obtained or a binding commitment must be obtained without access to direct authority, there begins lateral leadership [41].

Becker subsumes that any manager who is unable to establish good cooperation beyond the hierarchical order and forge alliances will have substantial disadvantages as a leader [3].

In outsourcing collaborations, according to Useem and Harder, managers must have the ability to get services organized outside their organization, rather than instructing them within the organization as they used to. This requires lateral leadership [41].

According to Bruch, a successful outsourcing project requires a form of inter-company coordination that is fundamentally different from the traditional order placement [5].

Managers need to be able to coordinate and succeed in outsourcing projects between partners with different goals [41].

It can be stated that the concept of lateral leadership is based on the use of influence mechanisms of understanding, trust and power. Lateral leadership takes place continuously, in any organization and mainly outside the formalorganization.

\subsection{The mechanisms of influence understanding, trust and power}

Organizational science identifies the means by which behavioural expectations towards other persons can be enforced as mechanisms of influence. The term goes back to the works of NiklasLuhmann[28]. 
In each organization or group, processes of understanding, power and trust are used as mechanisms of influence that determine the behaviour of the group and the members among themselves. Processes of understanding, power and trust always take place simultaneously in the organisation [26].

Kühl summarizes that in the context of lateral leadership, the mechanisms of influence play a unique role since the hierarchy of the organization can only be used to a limited extent[16].

Luhmann subsumes that influence mechanisms are continuously used to achieve and maintain the positive attitude of the other [26].

Kühl leads to the fact that any kind of communication with colleagues, superiors or leaders is an attempt to come to an understanding. So, this means communication is always an attempt to convince the other person of one's own position or to understand the position of the other.

Kühl goes on to say that trust or distrust is unconsciously built up by every interaction between people and that own and foreign power resources are shown and classified in order to prepare or parry later exercise of power.

Trust and understanding also play an essential role in a hierarchy, as it is often wise to use factors other than the exercise of power, especially with regard to the motivation of the employees and the quality of the execution of a necessary performance [26].

The organisation cannot force, prohibit or require the formation of mechanisms of influence. They arise in the shadow of the organization, but the organization with its formal structure ensures that they do not exuberant. Extensive communication processes are shortened by the organization because here it is clearly determined by the formal structure to whom one is not accountable and obliged to provide information [26].

The lateral leaderalways searches for functional equivalents. This means that heis looking for an equivalent process, as in substitution for the process with which he is currently unable to get any further. For example, one can overcome a complex power play by a smart understanding[16].

It can be noted that mechanisms of influence are always in place in every organization. They arise beyond the formal organizational structure and thrive silentlyand in most cases are used tacitly. They offer a good alternative for executives to exert influence beyond the formal structure of the organisation, especially if there is no direct authority to direct.

\subsubsection{Understanding}

A definition of understanding stated that understanding is a voluntary and binding agreement between two or more parties[13].

Understanding can be understood as understanding the other person in such a way that new possibilities for action can be opened. Only if the other person is understood in his motive, a silent or open trade can be agreedupon [15].

Galliker describes communication as an essential objective of communication with other people. Galliker explains that communication requires a common language and shared knowledge. Equally important, however, in the context of an understanding, is that the parties also want to understand each other, in the sense that they want to reach a communicative agreement, that is, an understanding [13].

Kühl notes that whenever one of the two actors master critical zones of uncertainty, a tacit understanding can arise between the leader and the follower. A silent trade is completed by exchanging one service for the other. For example, in hospitals where doctors and nurses make a tacit competency agreement among themselves to achieve common goals in nursing [26].

Geschwill and Nieswandt notice that any conversation can be regarded as a negotiation [15].

It is a question of negotiating in a substantive manner, treating people and problems separately. Interests should be negotiated, not positions. Before each decision, different outcomes should be developed and weighed. The outcome of any understanding should be based on objective decision-making criteria. It is considered in every negotiation and as a fundamental motto in the leadership: Soft to the people, hard in the matter [15].

Within the framework of an understanding, a possible partial consensus should always be based first, and not a fundamental consensus should be sought from the outset. In negotiating an understanding, one should always be open to contingent solutions, i.e. jointly developed solutions that were not previously thought possible. In processes of understanding, interests should be identified and not insisted on different points of view. It is also possible to make partial compromises and isolate differences as a bargaining chip [15].

The benefits of the process of understanding are clear. As a coordination mechanism, it mobilizes the views, experiences and interests of the actors involved and thus reduces the motivation and control problem of the leaders [26]. 
Understanding promotes cognitive conformity and leads to a higher inner acceptance of the required task. In addition, understanding leads to a better emotional climate between the leader and the follower due to an affective agreement in the sense of mutual sympathy [1].

Kühl describes it as fundamentally risky to cooperate with each other and to reach an understanding since the goodwill of the other person cannot be accepted in every case. To give the other person the benefit of a doubt that an understanding will be adhered to in a binding manner, therefore, carries the risk of being disappointed since there is no sanctioning power within the framework of the understanding [26].

It can be stated that the influence mechanism of understanding offers the possibility of a voluntary and binding outcome of negotiations between two or more parties. A voluntary understanding has the advantage of creating a stronger commitment between the parties over other forms of influence.

\subsubsection{Trust}

Osterloh summarizes that almost everything can be regulated within the framework of the cooperation. This creates freedom, flexibility and risks that can be controlled by trust. Trust is, therefore, to be understood as a lubricant of cooperation. Trust reduces the transaction costs of human action. Transaction costs can be understood as market usage costs. They are incurred as search and information costs, negotiation and control costs as well as costs for enforcing agreements.

A study carried out by McKinsey in 1997 concluded that about one-third of all economic costs come from transaction costs. Weibel and Osterloh point out that trust is not possible without control and seems too risky, as fraud can occur again and again. Only through meaningful controls can such cases be detected at an early stage [33].

The authors show that too much trust in other people leads to the trustee being more often taken advantage of than a trustee who has only an average trust. The authors thus show that both excessive trust and excessive distrust correlate negatively with a person's economic success [6].

Luhmann sees distrust not as the opposite of trust or its absence, but as the functional equivalent of trust. This means that both mechanisms (trust and mistrust) can be used to reduce complexity in equal measure, which serves to maintain the ability to act in complex situations [22].

Luhmann, therefore, refers to relationships of trust as exchange relationships without a certainty equivalent. Trust is built up through reliability and predictability. Over time, a basis of trust is manifested between the actors, from which further actions can be carried out, which for the time being do not require any control [26].

Luhmann writes that trust reduces the immense complexity of modern life so that the actors remain able to act [31].

Zündorf notes that a basis of trust is like a self-reinforcing mechanism, which is built up all the faster, the more often an advance of trust is rewarded [26].

Luhmann summarizes that by being present of trust, a higher contingency of experience and action prevails. There is no need to fight power struggles and controls can be reduced to a minimum. However, trust is also very fragile. It can be destroyed by the slightest sign of abuse of trust [26].

A distinction must be made between personal trust and systemic trust. Both components of trust are often interdependent. For the trustworthiness of organizations, the primary example is perceived justice. This is, above all about fairness in the context of change and decision-making processes. Transparency also plays a decisive role in trust in organisations. This concerns the open and direct communication of decisions, changes and requirements[31].

Schweer describes some fundamental characteristics of trust in which there is a broad consensus in the context of interdisciplinary research on trust. These are risk, reciprocity, time and area specificity [31].

Lehmann-Willbrock and Kauffeld (2010) were able to demonstrate a connection between trust in colleagues and the organisation [19].

Möller also writes that trust must be developed. It is a process that, in Möller's view, eludes direct manufacturability[31].

Krause subsumes that leadership through trust is an act of the leader, with which he makes himself vulnerable to the followers and in which he expects trustworthy behaviour in return. In this respect, the two actors enter into a mutual dependency relationship, which can only be sustained if both actors continue to be well-received[22].

It can be said that trust is a mechanism of influence that must arise between the parties. Trust is not directly possible to construct but is based on the advance of trust of one party, which in turn must be reciprocated by the other party in order to enable the trust to last in the long term. Trust reduces the complexity of economic activity by minimizing control mechanisms as much as possible through the trust factor. 


\subsubsection{Power}

Elias refers to power as a constitutive element of any human relationship. This refers to the fact that power relationships arise wherever people meet. Elias summarizes that human society consists of numerous, elementary liaised and dependent individuals. In such a society, the development of power as an ordering force within the social relationship construct is required[10].

Giddens refers to power as a "transformative capacity of human action" that exists as a potential ability even if it is not exercised. Giddens summarizes that power and its exercise do not necessarily go along with conflict but can very well be based on consensus. This goes back to the view of Max Weber and his quote on consensus-based power[42].

Max Weber speaks of a rational rule in connection with legitimate power. In other words, a rule that is rationally justifiable [42].

Ameln summarizes that the legitimacy of power arises when power has come about in a formally correct, i.e. generally accepted, way. Han describes that power requires a space that carries it, affirms it, and legitimizes it. Power and its exercise are always required in social systems where the limits of understanding are exceeded due to the size of the system or other communicative bottlenecks[1].

Kühl summarizes that hierarchies mean that organizations are able to adapt to the specific requirements of their environment without having to consider the sensitivities of each member[24].

For this reason, the hierarchy refers to the hierarchy as a ranking differentiation based on assumed threat potentials [25].

Coolly subsumes that a high position in the hierarchy only means the mastery of one uncertainty zone among many [26].

The hierarchical position is just one of several sources of power [1].

Executives who rely only on their sanctioning power and disregard other influencing factors easily generate informal counter-power[30].

According to Crozier and Friedberg, power relies on the leader's control of insecurity zones. These are organizational rules in hierarchies that can limit or expand the scope of the leaders. Specialists gain an influential position by mastering expertise relevant to the organisation or its manager. privileged access to important customers, suppliers or other important or influential cooperation partners. Employees in the role of gatekeeper, draw power from privileged access to higher-ranking and influential individuals and control of important internal communication channels[8].

French and Raven summarize the following six sources of power. Reward power, coercive or punitive power, legitimized power, role model power, expert power and information power [12].

Influence and power relations are always subject to dynamism, as they are subject to the demand situation for scarce resources. Power can, therefore, not be understood as an attribute of an actor, but only as a characteristic of a social situation[22].

MacMillian and Jones summarize that the power potential of a controlled resource depends on three factors: whether there is any need for the resource, how scarce it actually is, and how much it can be substituted [1].

Power is to be seen in the context of lateral leadership not only in the form of hierarchical authority but as power from other sources of power, such as the control of internal and often informal communication, the use of expert knowledge or the use of important contacts with the environment. Kühl sums up that power depends on one's own relevance for others and on one's own non-replaceability. Kühl subsumes that power games are not dysfunctional for organizations, as power games often overcome blockages. Kühl describes power games as keeping the lubricant of the organizations moving [26].

The function of exercising power for the leader is, among other things, to reduce complexity and to absorb uncertainty, since he does not have to make his own decisions and must assume no or only conditional, back-delegated responsibility. The basis for such a discharge is the subordination and delegation of power to the executive [1].

A function of power is to enforce organizational rationalities and goals against different rationalities, goals and interests of the organization members. In this way, the actions of a group can be geared towards a common objective [1].

"Power is a symbolically generalized medium of communication that reduces contingency and complexity by making the acceptance of the reduction in complexity provided in advance by the authorized body" [1].

"Power can help reduce two of the core problems of organisations - uncertainty and complexity"[1].

Friedberg describes the exercise of power as an asymmetric but reciprocal exchange process between the leader and the follower. The leader exercises power and the follower accepts this instruction for certain reasons and executes the instruction, as he hopes for an advantage from execution[8].

The exercise of power is based on the fact that power is accepted by the follower A department head can only exercise power and give instructions as long as they are acknowledged and subsequently executed [26].

Managers are often only partially powerful, as they often quickly reach the limits of their capacity and competence. This means that a manager is only partially able to control the execution of his instructions or often, the greater the organization and leadership distance, even to assess professionally [1].

It can be summarized that power relations are always based on reciprocity between leader and follower, with Friedberg noting that this reciprocity is usually unbalanced in favour of the leader [22]. 
The exchange process is not self-evidently fair or unfair. In the long term, however, the follower must have an interest in maintaining the power relationship or at some point evade the power relationship [26].

Slabu and Guinote summarize that powerful people who want to gain control of the situation and, according to their role power, often succumb to the temptation to bypass the efforts of the understanding process in order to achieve their goals[38].

Numerous experiments have shown that power leads to behavioural changes. Powerful people often consider other people to be less important, have less empathy, and usually judge other people according to their own value categories. Characteristics such as self-assured appearance, determined behaviour in disregard of the feelings and interests of other people occur as a result of taking over the position of power [1].

Ameln summarizes that the authority of the hierarchical superior alone is not enough for the permanent exercise of power. Professional authority and trust are necessary prerequisites for good cooperation and continued legitimacy [1].

"With (sanctions) power, the motivation to go the much-vaunted "extra mile" is not to be achieved, but it is straightforwardly destroyed" [1].

It can be said that power can feed on many different sources and depends to a large extent on the domination of such zones of insecurity of the follower by the leader. Power is in demand wherever the limits of communication and where a quick, clear and binding decision is required due to communication or otherbottlenecks. However, decisions found through the exercise of power usually carry only a limited commitment of all parties involved and, in some cases, even generate resistance.

\subsection{Interaction of understanding, trust and power}

In this chapter, the interaction of the three mechanisms of influence is discussed in more detail, and thus, their functioning is presented in detail.

In order to shed more light on the mechanisms of influence power, understanding and trust, it is helpful to consider the following analogy from the complex of game theory. The analogy shows the mode of action and interaction of the three introduced mechanisms of influence.

As early as 1965, the researchers Rapoport and Chammahdescribed a phenomenon now known as the so-called prisoner dilemma. Rapoport and Chammah were two American professors of psychology and mathematics and have worked intensively on research on system theory and game theory. In connection with their research, they were the first to research and analyse the prisoner dilemma listed below in order to gain insights into game theory, system theory and systematic correlations of the three mechanisms of influence introduced above[35].

In this context, the following situation is described as the starting point:

Two criminals are accused of a common crime. Both are detained by law enforcement and taken to two separate cells without being given the opportunity to communicate with each other at any time.

In the course of the separate interrogations of the two prisoners, several possibilities of conduct arise for the two detainees.

Either could deny the crime. Assuming that crimes committed can only be investigated by the police by a confession of at least one of the two detainees or by a possible indictment of one of the detainees by his fellow inmate, this strategy could lead to both prisoners must be released at a time $\mathrm{X}$ without fear of further consequences. However, this action by both prisoners requires an understanding between the two, which was agreed in advance, based on the mutual trust that the other person in question, in no case deviates from the agreed strategy.

Another possibility would be for one of the two to accuse the other and to seek leniency. Suppose that this behaviour would result in the accused being sentenced to at least ten years in prison and of impunity and a new life in the witness protection programme for the leniency witness. The question, therefore, arises as to whether the trust of the two prisoners in the other is high enough to deny the offence further, or whether, in view of this perspective, a confession, including the accusation of the other prisoner, might be an alternative. If both detainees make a simultaneous confession, the sentence for both would mean only five years for conditional cooperation.

In the present case, it seems useful for both to deny at first or to testify for both at the same time. In any case, it depends on the behaviour of the other. If it can be trusted that he also denies, this is the best of all alternatives. This requires a high level of trust and prior understanding of the use of power in the run-up to the arrest. For example, in this context, the factor power may be that the prisoner knows that if he testifies, his family will be punished by previously unknown accomplices who have been left with consequences for the testimony. In the same way, however, the exercise of power may lie in the promise of the supply of the denier's family. The influence on the relevant insecurity zone of the prisoner, namely that he must reckon with consequences or benefits from external third parties for his family, represents the possible exercise of power. This constellation of the exercise of power by external third parties is repeatedly cited, especially in the context of the investigation into the machinations of organised crime[20]. 
The trust that the other person does not testify or claim leniency is sought by the police by preventing communication between the two prisoners. Thus, by preventing the use of influence mechanisms, the police will try to unsettle each of them by a possible confession of the other, possibly only faked by the police, and to destroy the trust between the two prisoners [35].

An overview of the possible options for action of the prisoners and their consequences for the two detainees can be found in the table below. Vertically, the options for action of prisoner A can be found. Horizontally, the options for action of prisoner B can be found. The consequences resulting from the options for action can be found in the white boxes for each of the prisoners in combination as the yearly details of the subsequent detention.

Table 1: Options of Prisoners Dilemma own Illustration after Dixit and Nalebuff[9]

\begin{tabular}{|c|c|c|}
\hline Prisoner B & Cooperation with A (Denial) & No Cooperation with A (Confession) \\
\hline Prisoner A & 0,0 & $-10,0$ \\
\hline Nooperation with B (Denial) & $0,-10$ & $-5,-5$ \\
\hline
\end{tabular}

The present case thus shows very well the mode of action of power, understanding and trust as specific mechanisms of influence or also in the interplay of the factors with each other in order to generate the desired behaviour. Only by preventing communication between the prisoners arises a dilemma from the situation since the use of the possible influencing factors is in any case based on the use of communication. If this is prevented, the influencing factors can no longer be used in full efficiency or at all. In this case, only the previously established effect remains due to influencing factors that were effectively consolidated before the termination of communication, as described above by the use of power or the building of trust or understanding in the run-up to the arrest [9].

The parties cannot achieve maximum benefit because they cannot communicate with each other.

In the context of the company, all three mechanisms of influence also run in parallel in most cases. Processes of understanding, power and trust play a role in every verbal and non-verbal communication in every conceivable organisation. An influence mechanism can be sought at a time, which replaces the mechanism which just cannot be used [26]. It can be stated that in any organisation, including hierarchically organised and given authority, the influencing factors described above play a role. For the leader in the classical hierarchical organization, only the aspect of the authority of instruction and disciplinary authority and thus the control of essential zones of uncertainty of the leaders is added. The supervisor with authority to issue instructions can have a significant influence on the recruitment, remuneration, promotion and thus on the careers of subordinates. This gives him another aspect of the exercise of power. This aspect of the exercise of power lacks in lateral leadership. But also, the supervisor with authority to issue instructions does well to use the influence mechanism power only in a very dosed manner and to make greater use of the mechanisms of influence of trust and understanding, especially in the sense of sustainable and motivating leadership[3].

It can be stated that the mechanisms of influence are mutually interdependent, the influence factors are understanding, trust and the exercise of power. The mechanisms of influence can be substituted with each other and must be used individually, depending on the management situation. The interplay of the mechanisms of influence only works in close interaction and with the use of all three mechanisms of influence. The complete elimination of an influence mechanism disturbs the equilibrium of the mutual influence so significantly that the conduct is significantly tricky.

It can be stated, however, that up to now no empirical research is available on the origin, demarcation and interaction of the influencing factors. Stefan Kühl identifies the influencing factors in his work but deliberately leaves open whether the named three influencing factors form a self-contained unit or whether there may be other influencing factors, which have not yet been named [26].

In the context of this work and with the method of qualitative content analysis, it is unfortunately not possible to finally determine whether the three influencing factors form a self-contained system or whether other influencing factors play a role. Future research must address and clarify this issue. It would be desirable if an investigation were to provide empirical evidence of the extent to which the three influencing factors stand for themselves or must be supplemented by other influencing factors. 
An examination in which form the influencing factors play a role in the reality of day-to-day leadership would be desirable, apart from the well-known theory of lateral leadership. This could be achieved through a case study of expert interviews.

\section{CONCLUSIONS}

The results of the literature analysis have shown that the concept of lateral leadership is based on the three pillars of Understanding, Trust and Power. These named three pillars are influencing factors of leadership. The concept of lateral leadership can certainly be presented as established. It goes back to the work of NiklasLuhmann, who described the interactions of leadership factors in organizations as early as 1964 [28].

Further primary considerations on influencing factors in organizations were made by Klimecki [21].

Current work on the concept of lateral leadership and the influencing factors of leadership were presented by Prof. Dr. Stefan Kühl, a sociologist at Bielefeld University [26].

When analysing the literature, it quickly becomes clear that the concept of lateral leadership is more than a leadership style or a leadership concept. The named influencing factors of lateral guidance can claim to be fundamentally applicable in any management situation. They represent fundamental influencing factors, which are present at any time in more or less stable form in every management situation.

The existing research question, 'Is the concept of Lateral Leadership a fundamental Leadership approach or only a limited leadership method?' can thus be answered as follows.

The concept of lateral leadership is a fundamental leadership approach that is universally valid as a leadership concept in any leadership situation, especially beyond situations in which authority cannot be accessed.

\section{REFERENCES}

[1] Ameln, F.v. und P. Heintel, 2016. Power in Organisations. [in GER: Macht in Organisationen]. Wiesbaden: Schäfer Poeschel. ReiheSystemisches Management. ISBN 978-3-7992-7012-0.

[2] Bass, B.M. und B.J. Avolio, 1994. Improving organizational effectiveness through transformational leadership. Thousand Oaks, California: Sage Publications. ISBN 080395235X.

[3] Becker, F., 2015. Psychology of employee leadership. [in GER: Psychologie der Mitarbeiterführung] [online]. Wiesbaden: Springer. essentials. ISBN 978-3-658-07275-9. Verfügbarunter: http://dx.doi.org/10.1007/978-3-658-07276-6

[4] Blake, R.R., J.S. Mouton, L.B. Barnes und L.E. Greiner, 1964. Breakthrough in organization development. Harvard business review : HBR, 42(6), 133155. Harvard business review : HBR.

[5] Bruch, H., 1998. Outsourcing. Konzepte und Strategien, Chancen und Risiken [online]. Wiesbaden: Gabler Verlag. ISBN 978-3-663-05952-3. Verfügbarunter: http://dx.doi.org/10.1007/978-3-663-05951-6

[6] Butler, J., P. Giuliano und L. Guiso, 2016. The right amount of trust. Journal of the European Economic Association, 14(5), 1155-1180. Journal of the European Economic Association.

[7] Carlyle, T., 1888. On heroes, hero-worship and the heroic in history. London: Chapman \& Hall. Shilling edition of Thomas Carlyle's works.

[8] Crozier, M. und E. Friedberg, 1979. Power and Organisation. [in GER: Macht und Organisation]. Königstein/Ts.: Athenäum-Verlag. Sozialwissenschaft und Praxis. Bd. 3. ISBN 3761082118.

[9] Dixit, A.K. und B. Nalebuff, 2018. Gaming theory for Beginners. [in GER: SpieltheoriefürEinsteiger]. Stuttgart: Schäffer-Poeschel Verlag. ISBN $379104141 X$.

[10] Elias, N., 1970. Basic Questions of Sociology. [in GER: Grundfragen der Soziologie]. München: Juventa-Verl.

[11] Fleishman, E. and E. Harris, 1962. Patterns of Leadership behavior related to employee grievances and turnover [online]. Personnel Psychology, 15(1), 43-56. ISSN 0031-5826. Verfügbarunter: doi:10.1111/j.1744-6570.1962.tb01845.x

[12] French, J.R.P. und B. Raven, 1959. The bases of social Power. In: D. Cartwright, Hg. Studies in social power. Ann Arbor Mich.: Univ. of Michigan, S. $150-167$.

[13] Galliker, M.B. und D. Weimer, 2006. Psychology of Understanding. [in GER: Psychologie der Verständigung] [online]. Stuttgart: Kohlhammer. Einführungen und Allgemeine Psychologie. ISBN 3-17-018848-8. Verfügbarunter: http://gbv.eblib.com/patron/FullRecord.aspx?p=1561824

[14] Geramanis, O. und K. Hermann, Hg., 2016. Leadership in uncertain times. [in GER: Führen in ungewissenZeiten] [online]. Wiesbaden: Springer Gabler. uniscope. Publikationen der SGO Stiftung. ISBN 978-3-658-11226-4. Verfügbarunter: http://dx.doi.org/10.1007/978-3-658-11227-1

[15] Geschwill, R. und M. Nieswandt, 2016. Lateral Management. [in GER: Laterales Management]. Wiesbaden: Springer Fachmedien Wiesbaden. ISBN 978-3-658-11131-1.

[16] Grote, S., Hg., 2012. The Future of Leadership. [in GER: Die Zukunft der Führung] [online]. Berlin: Springer. ISBN 978-3-642-31051-5. Verfügbarunter: http://dx.doi.org/10.1007/978-3-642-31052-2

[17] Hersey, P. und K.H. Blanchard, 1977. Management of organizational behavior. Utilizing human resources. 3. ed. Englewood Cliffs, N.J.: Prentice-Hall. ISBN 0135488753.

[18] Jung, R.H., J. Bruck und S. Quarg, 2008. Basics of Leadership. 3rd Edition. Berlin: Erich Schmidt. ESV basics. ISBN 9783503112401.

[19] Kauffeld, S., Hg., 2014. Work-, Organisational- and Personal Psychology for Bachelor. [in GER: Arbeits-, Organisations- und Personalpsychologiefür Bachelor]. 2., überarb. Aufl. Berlin: Springer. Springer-Lehrbuch. ISBN 978-3-642-42064-1. 
[20] Kleinhenz, S., 2016. The Dark Side of Power. [in GER: Die dunkleSeite der Macht] [online]. Wiesbaden: Springer. essentials. ISBN 9783658123185. Verfügbarunter: http://gbv.eblib.com/patron/FullRecord.aspx? $=4337445$

[21] Klimecki, R.G., 1985. LateraleKooperation. Zur Analyse und Gestaltung der ZusammenarbeitzwischenAbteilungen in der Unternehmung. SchriftenzumPersonalwesen. ISBN 3258034893.

[22] Krause, D.E., 2010. Power and Trust in Innovationprocesses. [in GER: Macht und Vertrauen in Innovationsprozessen]. Wiesbaden: Gabler. ISBN 9783-8349-2444-5.

[23] Kuckartz, U., 2016. Qualitative Content Analysis. [in GER: Qualitative Inhaltsanalyse] [online]. 3., überarbeiteteAuflage. Weinheim: BeltzJuventa. GrundlagentexteMethoden. ISBN 978-3-7799-3344-1. Verfügbarunter: http://www.content-select.com/index.php?id=bib_view\&ean=9783779943860

[24] Kühl, S., 2013. Organizations. A systems approach. Farnham u.a.: Gower. Gower applied research. ISBN 978-1-4724-1341-3.

[25] Kühl, S., 2015. The Rainmaker Phenomenon. [in GER: Das Regenmacher-Phänomen]. 2nd Edition. Frankfurt, M.: Campus-Verl. ISBN 3593502941.

[26] Kühl, S., 2017. Lateral Leadership. [in GER: LateralesFühren] [online]. Wiesbaden: Springer VS. Management Kompakt. ISBN 978-3-658-13428-0. Verfügbarunter: http://dx.doi.org/10.1007/978-3-658-13429-7

[27] Lewin, K. und D. Cartwright, 1951. Field theory in social science. Selected theoretical papers.

[28] Luhmann, N., 1964. Functions and Consequences of formal organisation. [in GER: Funktionen und Folgenformaler Organisation]. 3rd Edition. Berlin Duncker und Humblot. Schriftenreihe der Hochschule Speyer. Bd. 20. ISBN 3428026136.

[29] Luhmann, N., 2018. Trust and Power. New York: John Wiley \& Sons. ISBN 1509519467.

[30] Matys, T., 2014. Power, Control and Decisions in Organsations. [in GER: Macht, Kontrolle und Entscheidungen in Organisationen] [online]. 2nd Edition. Wiesbaden: Springer VS. ISBN 978-3-658-01625-8. Verfügbarunter: http://dx.doi.org/10.1007/978-3-658-01626-5

[31] Möller, H., Hg., 2012. Trust in Organisations. [in GER: Vertrauen in Organisationen]. Wiesbaden: VS Verlag fürSozialwissenschaften. ISBN 978-3531-18118-9.

[32] Nerdinger, F.W. und G. Blickle, 2014. Work and Organisational Psychology. [in GER: Arbeits- und Organisationspsychologie] [online]. 3.rd Edition. Berlin: Springer. Springer-Lehrbuch. ISBN 9783642411298. Verfügbarunter: http://dx.doi.org/10.1007/978-3-642-41130-4

[33] Osterloh, M. und A. Weibel, 2006. Investment in Trust. [in GER: InvestitionVertrauen]. Wiesbaden: Gabler. ISBN 978-3-409-12665-6.

[34] Piccolo, R.F., J.E. Bono, K. Heinitz, J. Rowold und E. Duehr, 2012. The relative impact of complementary leader behaviors. Which matter most? The leadership quarterly : LQ : an international journal of political, social and behavioral science, 23(3), 567-581. The leadership quarterly : LQ : an international journal of political, social and behavioral science.

[35] Rapoport, A., A.M. Chammah und C.J. Orwant, 1970. Prisoner's dilemma. A study in conflict and cooperation. 2. print. Ann Arbor, Mich.: Univ. of Michigan Press. Ann Arbor paperbacks. 165. ISBN 0472756028.

[36] Rosenstiel, L. und R. Wegge, Hg., 2002. Organisational Sociology. Wiesbaden: Westdt. Verl. ISBN 3-531-13999-1.

[37] Schreyögg, G. und T. Lührmann, 2006. Leadership Identity. [in GER: Führungsidentität]. ZeitschriftFührung + Organisation : ZfO, 75(1), 11-16. ZeitschriftFührung + Organisation : ZfO.

[38] Slabu, L. und A. Guinote, 2010. Getting what you want: Power increases the accessibility of active goals [online]. Journal of Experimental Social Psychology, 46(2), 344-349. ISSN 00221031. Verfügbarunter: doi:10.1016/j.jesp.2009.10.013

[39] Stöwe, C. und L. Keromosemito, 2013. Leading without hierarchy - Lateral Leadership. [in GER: FührenohneHierarchie - LateraleFührung]. Wiesbaden: Springer Fachmedien Wiesbaden. ISBN 978-3-8349-3975-3.

[40] Tannenbaum, A.S., 1973. Social psychology of the work organization. Social science paperbacks. ISBN 422755001.

[41] Useem, M. und J. Harder, 2000. Leading Laterally in Company Outsourcing. Sloan Management Review, 2000(2), 25-36. Sloan Management Review.

[42] Weber, M., 2012. Economy and Society. [in GER: Wirtschaft und Gesellschaft]. Altenmünster: Jazzybee Verlag. ISBN 9783849612252.

[43] Wunderer, R. und W. Grunwald, 1980. Leadership. [in GER: Führungslehre]. Berlin. ISBN 3110078856. 